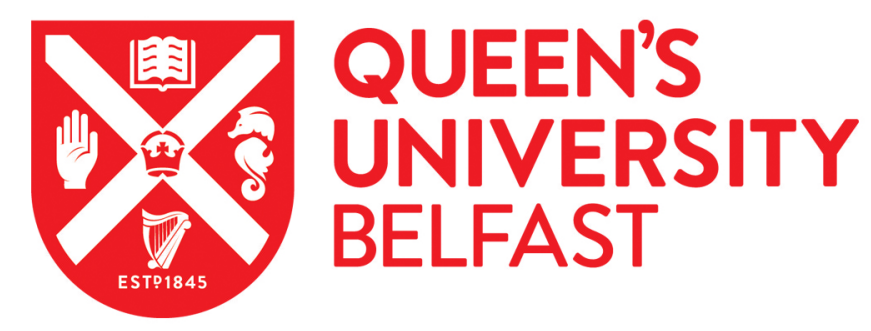

\title{
Exploring the photocatalytic hydrogen production potential of titania doped with alumina derived from foil waste
}

\author{
Osman , A. I., Skillen, N. C., Robertson, P. K. J., Rooney, D. W., \& Morgan, K. (2020). Exploring the \\ photocatalytic hydrogen production potential of titania doped with alumina derived from foil waste. International \\ Journal of Hydrogen Energy. https://doi.org/10.1016/j.ijhydene.2020.02.065
}

\section{Published in:}

International Journal of Hydrogen Energy

\section{Document Version:}

Peer reviewed version

Queen's University Belfast - Research Portal:

Link to publication record in Queen's University Belfast Research Portal

\section{Publisher rights}

(c) 2020 Elsevier Ltd.

This manuscript version is made available under the CC-BY-NC-ND 4.0 license http://creativecommons.org/licenses/by-nc-nd/4.0/,which permits distribution and reproduction for non-commercial purposes, provided the author and source are cited.

\section{General rights}

Copyright for the publications made accessible via the Queen's University Belfast Research Portal is retained by the author(s) and / or other copyright owners and it is a condition of accessing these publications that users recognise and abide by the legal requirements associated with these rights.

Take down policy

The Research Portal is Queen's institutional repository that provides access to Queen's research output. Every effort has been made to ensure that content in the Research Portal does not infringe any person's rights, or applicable UK laws. If you discover content in the Research Portal that you believe breaches copyright or violates any law, please contact openaccess@qub.ac.uk. 


\title{
Exploring the photocatalytic hydrogen production potential of titania doped with alumina derived from foil waste
}

\author{
Ahmed I. Osman ${ }^{a, b, c^{*}}$, Nathan C. Skillen ${ }^{b^{*}}$, Peter K.J. Robertson ${ }^{b}$, David W. Rooney ${ }^{b}$, Kevin Morgan ${ }^{a, b^{*}}$
}

a. Centre for Advanced Sustainable Energy, David Keir Building, Stranmillis Road, Belfast, BT9 5AG, UK.

b. Sustainable Energy Research Centre, School of Chemistry and Chemical Engineering, Queen's University Belfast, BT9 5AG, UK.

c. Chemistry Department, Faculty of Science, South Valley University, Qena 83523 - Egypt

Email: aosmanahmed01@qub.ac.uk;n.skillen@qub.ac.uk; kmorgan08@qub.ac.uk

\begin{abstract}
The multifunctional potential of a catalyst previously synthesised for thermal processes is explored by investigating its activity for photocatalytic production of $\mathrm{H}_{2}$ from glycerol, a by-product from the manufacture of bio-diesel. The studied catalyst contains $\mathrm{TiO}_{2}$ doped with $\mathrm{Al}_{2} \mathrm{O}_{3}$ that was derived from aluminum foil waste. This catalyst showed higher photocatalytic activity than the analogous catalyst prepared with a commercial $\mathrm{Al}_{2} \mathrm{O}_{3}$. Pt and $\mathrm{Pd}$ act as electron traps while the $\mathrm{Al}_{2} \mathrm{O}_{3}$ demonstrated a promotional effect, partially through proton donation. Under optimum conditions, a steady-state of 4.2 millimole $\mathrm{H}_{2} \mathrm{gTiO}_{2}{ }^{-1} \mathrm{hr}^{-1}$ was produced, which is comparable to the 4.7 millimole $\mathrm{H}_{2} \mathrm{gTiO}_{2}{ }^{-1} \mathrm{hr}^{-1}$ obtained with $\mathrm{Pt}_{-} \mathrm{TiO}_{2}$, which is a standard photocatalytic material. It should be noted that the reported $\mathrm{Pt} / \mathrm{Pd} / \mathrm{TiO}_{2}-\mathrm{ANFL}$ catalyst has not yet been optimised and so this result is encouraging. It is hoped that these findings can inspire more sustainable and less expensive hydrogen production, including from biomass feedstocks such as glycerol.
\end{abstract}

KEYWORDS: Hydrogen production; glycerol; aluminium foil waste; photocatalysis 


\section{Introduction}

The deployment of cost-effective catalyst supports with low power technologies such as photocatalysis presents the potential to develop more favourable systems. Photocatalysis is a lightinduced chemical reaction during which electron-hole charge carriers are generated that are capable of undergoing redox reactions on the surface of an active material. Since the initial publication by Fujshima and Honda in 1972 [1], photocatalytic technology has been deployed over a diverse range of fields including water splitting [2] and reduction [3], $\mathrm{CO}_{2}$ reduction[4], water disinfection [5] and air purification [6]. Moreover, a number of novel photocatalytic materials have now been reported in the literature for each of these applications [7-13].

As an application, $\mathrm{H}_{2}$ production remains one of the most challenging yet promising domains of photocatalysis. Pure water splitting, however, is both thermodynamically unfavourable and limited by a number of stringent requirements. As such, the use of sacrificial electron donors (SEDs) which are irreversibly oxidised and thus improve recombination and suppress back reactions, present a more viable option. Previously reported SEDs include alcohols [14], oxalic acid [3] and acetic acid [15]. An issue with the majority of these compounds is their use in current industrial processes and commercial value, both of which cannot be offset with the potential $\mathrm{H}_{2}$ produced. As a result, focus has shifted to utilising alternative products such as cellulose [16,17] and glycerol [18]. As a feedstock, glycerol is an excellent choice as stoichiometrically it can generate a high yield of hydrogen and glycerol is a by-product (10\% by volume) of biodiesel production and is generated in high volume with relatively low commercial value[19]. With the USA and Europe both producing 1.8 billion gallons of bio-diesel each year, this means there is a significant sustainable feedstock of glycerol available [19]. A number of publications have shown the potential of glycerol including Bowker et al. [18] who stated that $\mathrm{H}_{2}$ evolution from glycerol was four times greater over $\mathrm{Pd}-\mathrm{TiO}_{2}$ than $\mathrm{Au}-\mathrm{TiO}_{2}$. Estahbanati et al. [20] also reported on the optimum conditions they established for $\mathrm{H}_{2}$ to glycerol conversion: $50 \%$ glycerol $(\mathrm{v} / \mathrm{v}), 3.9 \mathrm{gL}^{-1}$ catalyst, $3.1 \% \mathrm{Pt}$ and a $\mathrm{pH}$ of 4.5. Furthermore, Jiang et al. [21] identified the role of the co-catalyst Pt and its deposition route to be crucial for glycerol reforming.

Usually alumina supports are produced from bauxite ore, which is mined in countries such as West Africa, the West Indies and Australia. It causes massive environmental damage by generating considerable levels of waste such as tailings, red mud, emissions of perfluorocarbon and $\mathrm{CO}_{2}$ gases during the production process [22].

The conversion of aluminium foil waste (AFW) into mesoporous $\gamma-\mathrm{Al}_{2} \mathrm{O}_{3}$ (catalyst/support) using a cost-effective green synthetic route is highly desirable. Recently, we reported an eco- 
friendly and less expensive synthesis of mesoporous $\gamma-\mathrm{Al}_{2} \mathrm{O}_{3}$ from $\mathrm{AFW}$ where the produced mesoporous alumina catalyst $\left(\gamma-\mathrm{Al}_{2} \mathrm{O}_{3}\right)$ had surface and bulk characteristics better than commercial alumina in relation to the surface structure [22,23]. A further additional benefit is that our alumina is generated from $\mathrm{AFW}$, therefore reducing the need for landfill.

Presented here is the use of our previously reported AFW catalyst support [22,24] for the application of photocatalytic reforming of glycerol to $\mathrm{H}_{2} . \mathrm{TiO}_{2}, \mathrm{Pd}$ and $\mathrm{Pt}$ were loaded onto the AFW derived $\mathrm{Al}_{2} \mathrm{O}_{3}$ and used in conjunction with a propeller fluidised photo reactor (PFPR) [3] under low power UV irradiation. As a proof of concept study, the photocatalytic activity and stability of the material are reported.

\section{Experimental}

The AFW was collected from the laboratories in the David Keir building at Queen's University Belfast. The chemicals used in the present study were all analytical grade and most were supplied by Aldrich, UK. These included glycerol, $\mathrm{Al}\left(\mathrm{NO}_{3}\right)_{3} \cdot 9 \mathrm{H}_{2} \mathrm{O}, \mathrm{Pd}\left(\mathrm{NO}_{3}\right)_{2} .2 \mathrm{H}_{2} \mathrm{O}, \sim 40 \% \mathrm{Pd}$ basis, Nano-powder $\mathrm{TiO}_{2}, 99.7 \%$, anhydrous aluminium chloride $\left(\mathrm{AlCl}_{3}\right)$, nitric acid $(\geq 65 \%)$, hydrochloric acid $(\geq 37 \%), \mathrm{Hg}\left(\mathrm{NO}_{3}\right)_{2} \cdot \mathrm{H}_{2} \mathrm{O}$ ( $\geq 99.99 \%$ trace metals basis), pyridine anhydrous (99.8\%), $\mathrm{AgNO}_{3}(\geq 99.0 \%)$ and ammonia solution (35\%). $\mathrm{Pt}\left(\mathrm{NH}_{3}\right)_{4}(\mathrm{OH})_{2}$, assay 9.09\% was obtained from Alfa Aesar. $\mathrm{TiO}_{2} \mathrm{P} 25$ was supplied by Evonik Degussa. All gases $\left(\mathrm{H}_{2}, \mathrm{He}, \mathrm{Ar}\right.$ and $\left.\mathrm{N}_{2}\right)$ were obtained at $100 \%$ purity from BOC gases, UK.

\section{The preparation of $\mathrm{AlCl}_{3} \cdot 6 \mathrm{H}_{2} \mathrm{O}$ and $\mathrm{Al}\left(\mathrm{NO}_{3}\right)_{3} .9 \mathrm{H}_{2} \mathrm{O}$ single crystal}

The preparation method is described elsewhere ${ }^{1}$. While the AFW was collected from our laboratory, any variance as a result of previous use can be negated through hydrothermal treatments. The AFW, in this case, was previously used for insulation of heat traced gas lines. The AFW was dissolved in acidic solutions, and then the solution was kept under a desiccator until different single crystallites formed. After the recrystallisation, a novel facile preparation route was followed to prepare the $\gamma-\mathrm{Al}_{2} \mathrm{O}_{3}$ via ammonia precipitation. The alumina support prepared from the AFW designated as ANFL.

\section{Preparation of modified ANFL}


The preparation of a bimetallic Pd-Pt loaded on a dual component support ( $\mathrm{TiO}_{2} / \mathrm{ZSM}-5(80)$ ) has been described in previous work $^{15}$. This previous preparation was for alkane oxidation applications, and the same metal loadings were utilised in the current work. The catalysts were prepared using a wet impregnation method with the aid of sonication using a catalyst composition of $5 \% \mathrm{Pd}+2 \% \mathrm{Pt}+17.5 \% \mathrm{TiO}_{2}+75.5 \% \mathrm{Al}_{2} \mathrm{O}_{3}$ (ANFL). Pure ANFL support was placed in a vial and the mass of metal precursor solution or slurry, required to give $5 \mathrm{wt} \%$ palladium and $2 \mathrm{wt} \%$ platinum loading was added followed by $\mathrm{TiO}_{2}$ to give $17.5 \mathrm{wt} \%$ in deionised water. The mixture was sonicated at $80{ }^{\circ} \mathrm{C}$, under a $45 \mathrm{kHz}$ frequency for $3 \mathrm{hrs}$. All mixtures were dried at $120{ }^{\circ} \mathrm{C}$ overnight in an oven before being calcined in air at $500{ }^{\circ} \mathrm{C}$ for 4 hrs with a heating ramp of $2{ }^{\circ} \mathrm{C}$ $\min ^{-1}$. Finally, the produced catalysts were further washed with hot deionised water until no chlorine was detected using $\mathrm{AgNO}_{3}$. A benchmark catalyst was prepared using the same procedure mentioned above with a composition of $5 \% \mathrm{Pd}+2 \% \mathrm{Pt}+17.5 \% \mathrm{TiO}_{2}+75.5 \%$ commercial alumina and was designated as commercial.

\section{Determination of Chlorine Content}

The chlorine content was measured using Oxygen Flask analysis by subjecting the sample to combustion in an oxygenated flask containing water, followed by shaking; in which chlorine dissolved in water forming $\mathrm{HCl}$ solution, the latter solution was titrated with $0.02 \mathrm{M} \mathrm{Hg}_{2} \mathrm{NO}_{3}$ to obtain the percentage of chlorine. There was no chlorine detected in the samples after preparation.

\section{Catalyst Characterisation}

Brunauer-Emmett-Teller (BET) analysis was performed using a Micromeritics ASAP 2020 system. BET surface area and pore volume were measured by $\mathrm{N}_{2}$ adsorption and desorption isotherms at liquid nitrogen temperature $(77.15 \mathrm{~K})$. 
The acidity populations over the surface of catalysts were measured thermogravimetrically using the adsorption of pyridine as a probe molecule. Small portions $(50 \mathrm{mg})$ of each sample were pre-heated at $250{ }^{\circ} \mathrm{C}$ for $2 \mathrm{~h}$ in the air before the exposure to the probe molecule. $15-20 \mathrm{mg}$ of pyridine-covered samples were subjected to $\mathrm{TG}$ analysis on heating up to $600{ }^{\circ} \mathrm{C}$ (at $20{ }^{\circ} \mathrm{C} \mathrm{min}-1$ heating rate) in dry $\mathrm{N}_{2}$ (flow rate $=$ $40 \mathrm{~mL} \mathrm{~min}-1$ ). The mass loss due to desorption of pyridine from the acidic sites was determined as a function of total surface acidity as sites.g ${ }^{-1}$ cat. Determination of the concentration of Lewis and Brönsted acid sites on the pyridine-covered samples was performed using a Perkin Elmer-Spectrum 100 FT-IR spectrometer.

Transmission electron microscope (TEM) characterisation was performed using a Philips Tecnai F20 ST with a high tension of $200 \mathrm{kV}$ and point resolution of $0.24 \mathrm{~nm}$.

\section{Photocatalysis Testing}

All photocatalytic experiments were conducted in the PFPR, the full details of which can be found elsewhere ${ }^{4}$. In a typical experiment, $100 \mathrm{~mL}$ of a predetermined concentration of glycerol feedstock (typically $1 \mathrm{M}$ ) was added to the reactor along with $0.75 \mathrm{~g} \mathrm{~L}^{-1}$ of catalyst and stirred at $250 \mathrm{rpm}(2.5 \mathrm{dcV})$. The entire reactor system was sealed and purged with $\mathrm{N}_{2}$ at $150 \mathrm{~mL} \min ^{-1}$ for 20 min prior to any illumination. Upon completing purging, a sample was taken to confirm no $\mathrm{O}_{2}$ or $\mathrm{H}_{2}$ was present. The reactor propeller speed was then increased to $1200 \mathrm{rpm}(5.5 \mathrm{dcV})$ and the illumination started. 
Illumination was provided by two compact fluorescent non-integrated lamps (Phillips), powered by a dual ballast (Tridonic). Each lamp had an electrical power of $36 \mathrm{~W}$ and peak wavelength of $355 \mathrm{~nm}$. The lamps were positioned on either side of the PFPR at a distance of $5 \mathrm{~mm}$ from the annular glass body. The intensity of light at the quartz glass body of the PFPR was measured using a radiometer (UV-X) and was found to be $4.7 \mathrm{~mW} \mathrm{~cm}^{-2}$. An image of the PFPR under irradiation can be seen in Figure 1.

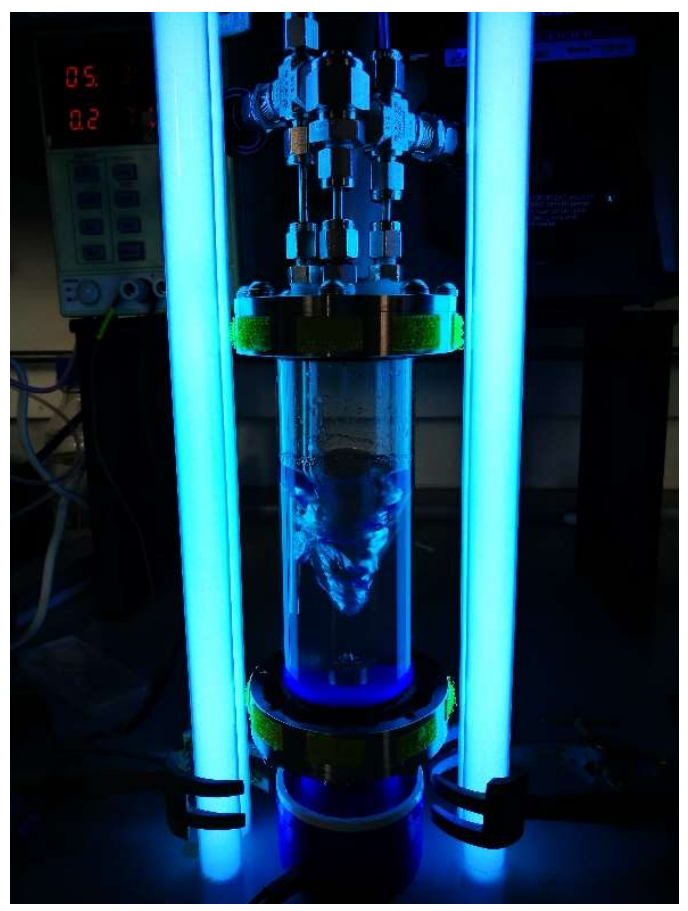

Figure 1: Image of the PFPR under irradiation from two $36 \mathrm{~W}$ compact fluorescent lamps

During the photocatalytic procedure, gas samples were taken periodically from the headspace of the PFPR and analysed by GC-TCD for the formation of $\mathrm{H}_{2}$. An Agilent Technologies 7280 A GC system was used coupled with a packed column (RESTEK, $2 \mathrm{~mm}$ ID) and a Thermal Conductivity Detector (TCD). The injector was operated at a temperature of $150{ }^{\circ} \mathrm{C}$, pressure of $26.1 \mathrm{psi}$ and a flow rate of $22.9 \mathrm{~mL} \mathrm{~min}^{-1}$. The flow rate in the column was $20 \mathrm{~mL} \mathrm{~min}^{-1}$ with an oven temperature of $50{ }^{\circ} \mathrm{C}$, while the detector was maintained at $200{ }^{\circ} \mathrm{C}$ with a flow rate of $5 \mathrm{~mL} \mathrm{~min}^{-1}$. Ar was used as the carrier gas. The detection of $\mathrm{H}_{2}$ was determined by comparison to a standard injection of pure $\mathrm{H}_{2}$, while quantification was determined from a calibration of known concentrations. 


\section{Results and Discussion}

The photoactivity of the various materials tested for $\mathrm{H}_{2}$ evolution are shown in Figure 2. With a loading of $\mathrm{TiO}_{2}$ onto the surface of the $\mathrm{Al}_{2} \mathrm{O}_{3}$ support structures, it was expected all the materials would exhibit photoactivity under UV irradiation. In contrast, when $\mathrm{TiO}_{2}$ was not present, no photoactivity was observed for the support material on its own. In the absence of both $\mathrm{Pt}$ and $\mathrm{Pd}, \mathrm{a}$ small amount of $\mathrm{H}_{2}$ was recorded with the rate increased significantly upon the addition of both cocatalysts. This confirmed that Pt and Pd were likely acting as reaction centres and electron traps to facilitate the reduction of protons to $\mathrm{H}_{2}$. Additionally, in the absence of irradiation and glycerol, no $\mathrm{H}_{2}$ was detected which confirmed the process was photo-induced and $\mathrm{H}_{2}$ was evolving from the irreversible conversion of glycerol.

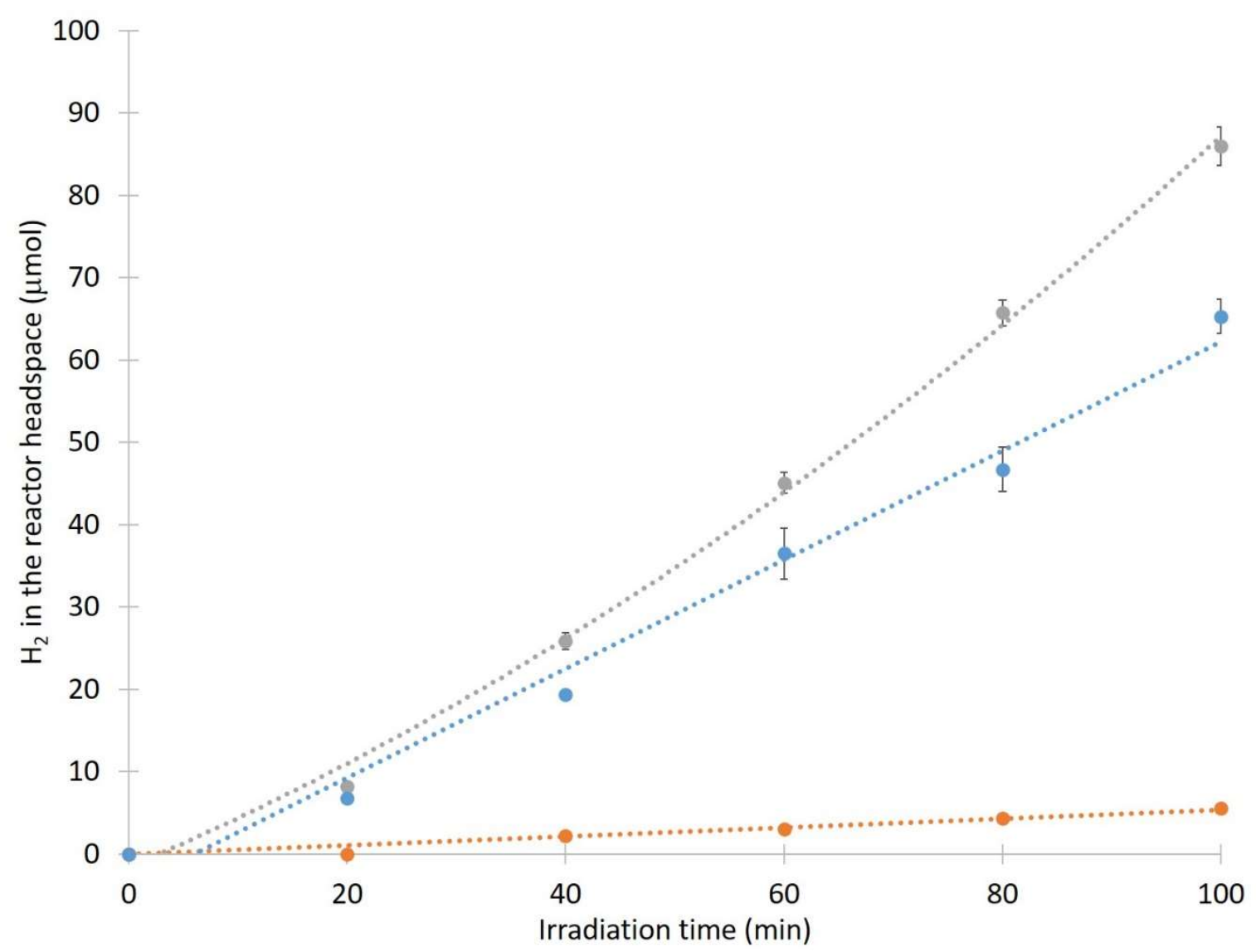

Figure 2: photocatalytic reforming of glycerol to $\mathrm{H}_{2}$ over various catalysts as a function of irradiation time. $\mathrm{H}_{2}$ evolution over $\mathrm{Pt} / \mathrm{Pd} / \mathrm{TiO}_{2}-\mathrm{ANFL}(\bullet), \mathrm{Pt} / \mathrm{Pd} / \mathrm{TiO}_{2}-$ commercial (•) and $\mathrm{TiO}_{2}-$ ANFL $\left({ }^{\circ}\right)$ 
Figure 2 also highlights the impact of the support materials (ANFL and commercial alumina) on photocatalytic $\mathrm{H}_{2}$ evolution. As already shown, the support on its own was not photoactive, yet was evidently capable of affecting the photocatalytic activity. The characterisation of the catalysts (Table 1) revealed the catalysts derived from commercial alumina and ANFL have similar surface areas: 278 and $264 \mathrm{~m}^{2} \mathrm{~g}^{-1}$, respectively. Furthermore, the pore volumes were 0.35 and $0.5 \mathrm{~cm}^{3} \mathrm{~g}^{-1}$ for commercial $\mathrm{Al}_{2} \mathrm{O}_{3}$ and ANFL catalysts, respectively. Despite having a lower surface area however, the ANFL catalyst interestingly showed up to $22 \%$ higher photocatalytic activity than the catalyst prepared using commercial alumina (Figure 2). This may be in part due to the ANFL catalyst having lower mass transfer limitations due to the larger pore volume. In general, however, an increase in photocatalytic activity is primarily achieved through improving charge separation and the availability of acceptor and donor species on the catalyst surface. Typically, this involves the presence of $\mathrm{OH}$ - for the generation of the $\mathrm{OH} \bullet$ at the valence band and a suitable electron scavenger (e.g. $\mathrm{O}_{2}$ or protons) at the conduction band.

Table 1: Surface area $\left(\mathrm{S}_{\mathrm{BET}}\left(\mathrm{m}^{2} \mathrm{~g}^{-1}\right)\right)$ and pore volume $\left(\mathrm{cm}^{3} \mathrm{~g}^{-1}\right)$ for acidic support derived from foil waste

\begin{tabular}{|c|c|c|c|c|}
\hline Catalyst & $\begin{array}{c}\text { SBET } \\
\left(\mathrm{m}^{2} \mathrm{~g}^{-1}\right)\end{array}$ & $\begin{array}{l}\text { Pore volume } \\
\qquad\left(\mathrm{cm}^{3} \mathrm{~g}^{-1}\right)\end{array}$ & $\begin{array}{c}\text { Total acidity } \\
\left.\text { A(sites } \mathbf{g}^{-1}\right)\end{array}$ & $\begin{array}{l}\text { Total acidity } \\
\left.\text { B(sites } \mathbf{~ m}^{-2}\right)\end{array}$ \\
\hline ANFL & 264 & 0.5 & 8.13 & 3.1 \\
\hline commercial & 278 & 0.35 & 6.91 & 2.5 \\
\hline
\end{tabular}

\footnotetext{
${ }^{\mathrm{a}}$ Total acidity $=\mathrm{A} \times 10^{20}$.

${ }^{\mathrm{b}}$ Acid density $=\mathrm{B} \times 10^{18}$.
} 
Interestingly, the characterisation of the support materials revealed the $\mathrm{Pt} / \mathrm{Pd} / \mathrm{TiO}_{2}-\mathrm{ANFL}$ catalyst to have significantly higher total acidity $\left(\right.$ sites $\mathrm{g}^{-1}$ ) than the commercial $\mathrm{Al}_{2} \mathrm{O}_{3}$ equivalent. The total acidity of the commercial $\mathrm{Al}_{2} \mathrm{O}_{3}$ catalyst in sites/g was $6.91 \times 10^{20}$, which was significantly increased to $8.13 \times 10^{20}$ in case of ANFL catalyst. The acid density of the ANFL was also higher than that of the commercial catalyst of $3.1 \times 10^{18}$ and $2.5 \times 10^{18}$, respectively, as shown in Table 1.

This higher level of acidity was likely due to increase the availability of protons at the surface of the ANFL support. Subsequently, the higher number of available protons may result in accelerated electron transfer to adsorbed protons at the conductance band of $\mathrm{TiO}_{2}$, which would increase $\mathrm{H}_{2}$ formation. Based on this, it can be shown that while the addition of the ANFL support did not alter the catalytic activity through changes to the parent photoactive material $\left(\mathrm{TiO}_{2}\right)$, it did provide an increased number of electron acceptor species (protons) and hence enhanced $\mathrm{H}_{2}$ formation. The impact of $\mathrm{Al}$ on the photocatalytic activity of $\mathrm{TiO}_{2}$ has previously been reported by Murashkina et al.[25]. Their report found that, as expected, the addition of Al resulted in an increase in the anatase fraction of mixed-phase $\mathrm{TiO}_{2}$ along with a decrease in particle size and subsequently an increase in the surface area of the material. Interestingly, the paper found that while the addition of $\mathrm{Al}$ to $\mathrm{TiO}_{2}$ did not alter the reaction sites, it did increase the concentration of them available and thus accelerated the rate of phenol degradation [25]. 

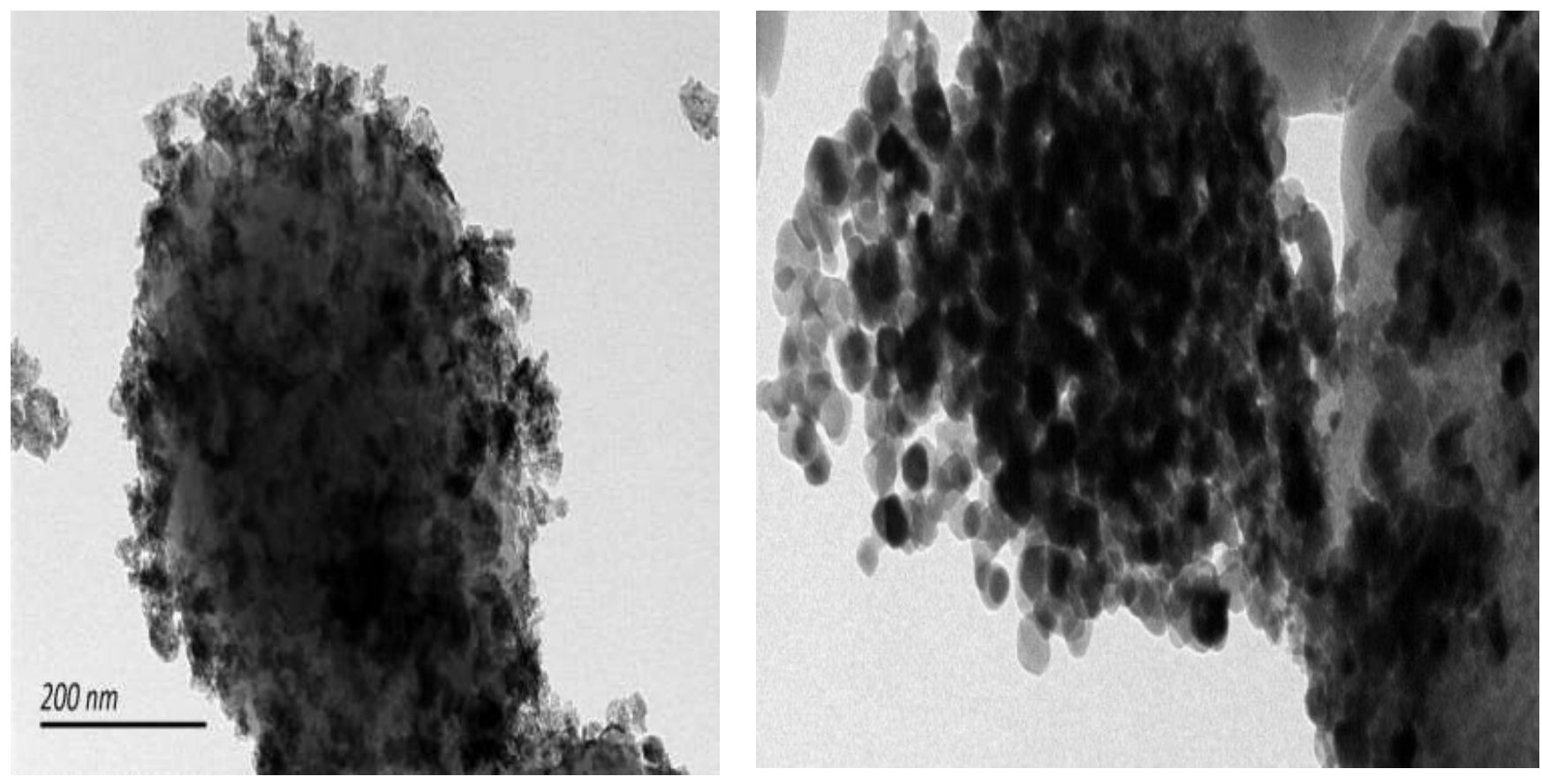

Figure 3: TEM images of $\mathrm{Pd}$, $\mathrm{Pt}$ and $\mathrm{TiO}_{2}$ loaded onto $\mathrm{Al}_{2} \mathrm{O}_{3}$ supports (ANFL).

While it was the presence of $\mathrm{TiO}_{2}, \mathrm{Pt}$ and $\mathrm{Pd}$ (see Figure 3) which primarily drove the photocatalytic reduction reaction in the current work, the increase in proton availability and affinity at the ANFL support was crucial for improved $\mathrm{H}_{2}$ generation. Equations 1-4 detail the typical process occurring during the photo-reforming of glycerol to $\mathrm{H}_{2}$. In order for photocatalytic $\mathrm{H}_{2}$ evolution to occur, a photon was adsorbed by $\mathrm{TiO}_{2}$ leading to photo-excitation (Equation 1) and subsequently, electron trapping by either Pd or Pt. Simultaneously however, OH- from the glycerolwater solution will lead to $\mathrm{OH} \bullet$ formation (Equation 2), which facilitates glycerol oxidation to a range of liquid phase products and protons (Equation 3). The liquid phase products include dihydroxyacetone, glycolaldehyde and glyceraldehyde which can occur via either direct hole or $\mathrm{OH} \bullet$ interaction. The key step in the formation of $\mathrm{H}_{2}$ from glycerol is this initial oxidation, which also releases protons. The release and increased availability of protons through the use of ANFL, resulted in the accelerated two-electron reduction of protons to $\mathrm{H}_{2}$ (Equation 4). Based on Equations 
1-4, the illustration in Figure 4 represents the proposed mechanism for photocatalytic glycerol reforming to $\mathrm{H}_{2}$ over $\mathrm{Pt} / \mathrm{Pd} / \mathrm{TiO}_{2}-\mathrm{ANFL}$.

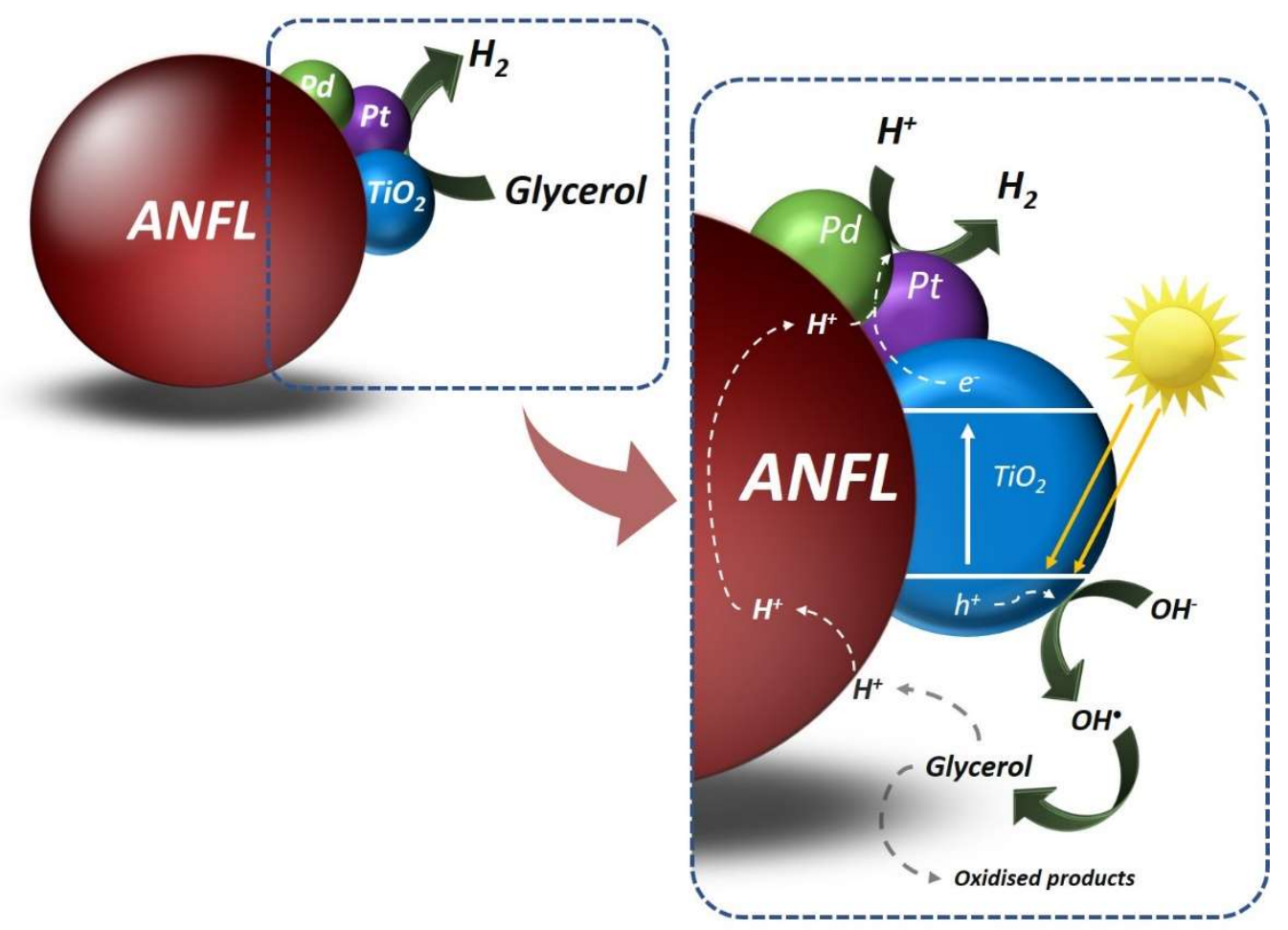

Figure 4: Illustration of the proposed mechanism of photocatalytic glycerol reforming over $\mathrm{Pt} / \mathrm{Pd} / \mathrm{TiO}_{2}-$ ANFL

Equation 1

Equation 2

Equation 3

Equation 4

$$
\begin{gathered}
\text { Photocatalyst }+h v=V_{h^{+}}+C B_{e^{-}} \\
V B_{h^{+}}+\mathrm{OH}^{-} \stackrel{\mathrm{TiO}_{2}}{\longrightarrow} \mathrm{OH} \cdot \\
\mathrm{C}_{3} \mathrm{H}_{8} \mathrm{O}_{3}+\mathrm{OH} \cdot+h^{+} \stackrel{\mathrm{TiO}_{2}}{\longrightarrow} C_{x} H_{y} \mathrm{O}_{z}+H^{+} \\
H^{+}+2 e^{-\stackrel{P d / P t}{\longrightarrow}} \mathrm{H}_{2}
\end{gathered}
$$

The $\mathrm{Pt} / \mathrm{Pd} / \mathrm{TiO}_{2}-\mathrm{ANFL}$ catalyst also showed stable activity over a prolonged irradiation time frame of $6 \mathrm{~h}$. This confirmed linear $\mathrm{H}_{2}$ formation and zero order kinetics with a rate constant of $0.95 \mu \mathrm{mol} \mathrm{min}^{-1}$. In addition, steady-state $\mathrm{H}_{2}$ production was also achieved after $180 \mathrm{~min}$ at a rate of 4.2 millimole $\mathrm{H}_{2} \mathrm{gTiO}_{2}{ }^{-1} \mathrm{hr}^{-1}$ (Figure 5). 


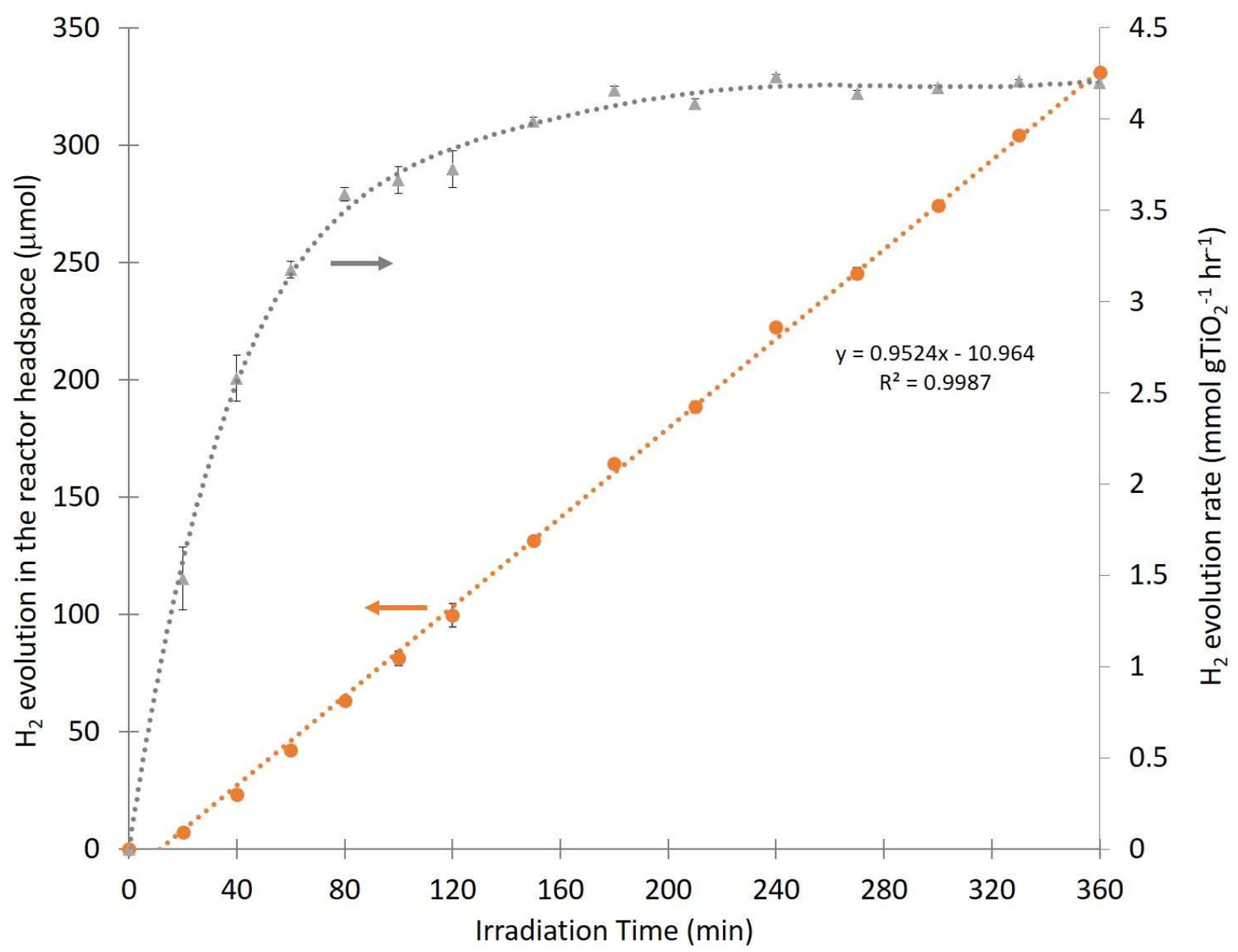

Figure 5: photocatalytic reforming of glycerol to $\mathrm{H}_{2}$ over $\mathrm{Pt} / \mathrm{Pd} / \mathrm{TiO}_{2}-\mathrm{ANFL}$ over prolonged irradiation $\left({ }^{\circ}\right)$ and the corresponding reaction rate $(\cdot)$

As $\mathrm{Pt} / \mathrm{Pd} / \mathrm{TiO}_{2}$-ANFL was evidently active, comparison to a standard catalyst used in this field $\left(0.5 \% \mathrm{Pt}-\mathrm{TiO}_{2} \mathrm{P} 25\right)$ was valuable. Under the same experimental conditions $0.5 \% \mathrm{Pt}_{-} \mathrm{TiO}_{2}$ was shown to be the optimum loading for $\mathrm{H}_{2}$ formation, achieving a rate constant of $5.9 \mu \mathrm{mol} \mathrm{min}$ ( $^{-1}$ (see Figure S1 and S2 in the Supplementary Information), which was significantly higher than that of $\mathrm{Pt} / \mathrm{Pd} / \mathrm{TiO}_{2}-\mathrm{ANFL}$. In order for an accurate comparison, however, the amount of photo-active material present should be taken into consideration. While a loading of $0.75 \mathrm{~g} \mathrm{~L}^{-1}$ was used in both experiments, in the case of ANFL this was not entirely photo-active material, as only $17.5 \%$ was $\mathrm{TiO}_{2}$. Therefore, recalculating the yields under these conditions as a function of 1 gram of active $\mathrm{TiO}_{2}$ material then it was found $0.5 \% \mathrm{Pt}_{-} \mathrm{TiO}_{2}$ produced 4.7 millimole $\mathrm{H}_{2} \mathrm{gTiO}_{2}^{-1} \mathrm{hr}^{-1}$ while 
$\mathrm{Pt} / \mathrm{Pd} / \mathrm{TiO}_{2}$-ANFL produced 4.2 millimole $\mathrm{H}_{2} \mathrm{gTiO}_{2}{ }^{-1} \mathrm{hr}^{-1}$. These numbers are clearly far more comparable than just the individual rates. Furthermore, this number is also within typical values previously reported in the literature for glycerol conversion to $\mathrm{H}_{2}$ using $\mathrm{Pt}-\mathrm{TiO}_{2}$ catalysts. The comparison between heterogeneous photocatalytic systems can often be challenging due to the number of parameters which can influence the activity such as irradiation intensity and time of exposure, catalyst and substrate concentration, reactor design and physical catalyst morphology. Therefore, comparison in this study has been based only on reaction rate as a function of irradiation time $\left(\mathrm{hr}^{-1}\right)$ and quantity of catalyst used $\left(\mathrm{gTiO}_{2}{ }^{-1}\right)$. A number of papers have used $\mathrm{Pt}-\mathrm{TiO}_{2}$ for glycerol reforming to $\mathrm{H}_{2}$ with a typical reported range of 1.5 to 4.3 millimole $\mathrm{gTiO}_{2}^{-1} \mathrm{hr}^{-1}$ which included the use of fluorinated $\mathrm{Pt}-\mathrm{TiO}_{2}$ and $\mathrm{Pt}$ on $\mathrm{TiO}_{2}$ nanotubes $[21,26,27]$. In addition, a rate of 1.23 and $0.9 \mathrm{gTiO}_{2}^{-1} \mathrm{hr}^{-1}$ was reported by Fujita et al. [28] and Liu et al. [29] respectively, who both utilised $\mathrm{NiO}\left(\mathrm{NiO}_{\mathrm{x}}-\mathrm{TiO}_{2}\right)$ in replace of $\mathrm{Pt}$ as a co-catalyst. While the reaction rate reported here is clearly within that achieved in previous papers, this paper is the first to achieve it using a catalyst support synthesised from AFW. It should also be noted that $0.5 \% \mathrm{Pt}$ on $\mathrm{TiO}_{2}$ has often been reported as the optimum co-catalyst loading [3], however, the co-catalysts present on ANFL are yet to be optimised for peak production. It has already been shown in multiple publications that $\mathrm{Pt}$ $[15,30]$, with its high work function $(5.5 \mathrm{eV})$, is typically the most active co-catalyst for $\mathrm{H}_{2}$ evolution. Therefore, it is feasible to assume that the $4.2 \mathrm{mmole}_{2} \mathrm{gTiO}_{2}^{-1} \mathrm{hr}^{-1}$ could be an underestimation and can be improved with modification to the co-catalyst ratio. This is the current focus of on-going work with a view towards optimising the catalyst.

The development of an eco-friendly and cost-effective catalyst material is largely dictated by first its initial activity and second, its stability over time. Figure 6 demonstrates the stability of the $\mathrm{Pt} / \mathrm{Pd} / \mathrm{TiO}_{2}-\mathrm{ANFL}$ catalyst for the evolution of $\mathrm{H}_{2}$ from glycerol over repeated runs. The catalyst and glycerol mass remained constant throughout the run with $\mathrm{N}_{2}$ being used to purge the system inbetween irradiation cycles to remove $\mathrm{H}_{2}$ from the gas headspace. Over a run of five cycles, 
$\mathrm{Pt} / \mathrm{Pd} / \mathrm{TiO}_{2}-\mathrm{ANFL}$ showed steady photoactivity and interestingly appeared to reach a stable state after two cycles. At cycle 5, a zero-order rate constant of $1.1 \mu \mathrm{mol} \mathrm{min}{ }^{-1}$ was achieved, which was $\mathrm{a} \sim 14 \%$ increase from cycle 1 . The data also confirmed the presence of an induction period, which was evident in Figure 2 and the first cycle of Figure 6. In a number of $\mathrm{H}_{2}$ evolving photocatalytic systems, an initial period of inactivity or an induction period is often observed [16]. The cause of this varies depending on the parameters which are being tested, however, it can often be due to the initial reduction of the co-catalyst or the adsorption of the target to the catalyst site.

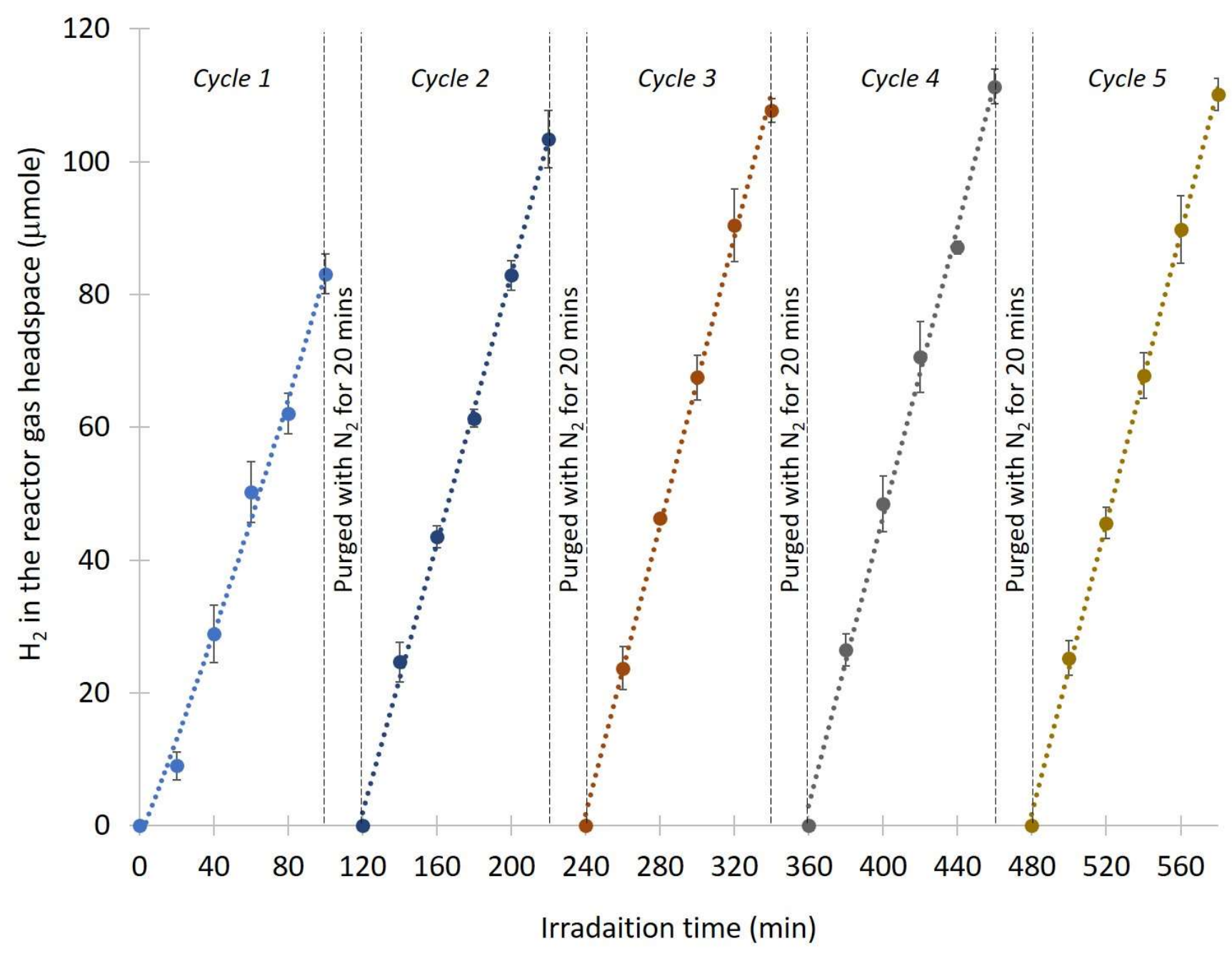

Figure 6: Photocatalytic reforming of glycerol to $\mathrm{H}_{2}$ over $\mathrm{Pt} / \mathrm{Pd} / \mathrm{TiO}_{2}-\mathrm{ANFL}$ and 5 experimental cycles as a function of irradiation time. The reactor was purged with $\mathrm{N}_{2}$ for 20 mins between each cycle while the reaction suspension (glycerol + catalyst) remained constant throughout. 
In the case reported here, despite a polynomial trend in the first cycle, a linear trend is observed from cycle two onwards. While the induction period in $\mathrm{H}_{2}$ evolving catalysts has been documented [16], it does not necessarily explain the increase in activity in the later cycles. One explanation could be the presence of partial oxidation products (Equation 3) which will remain in the liquid phase between cycles. Moreover, the formation of partial oxidation products would increase the concentration of protons at the surface of ANFL. With a high number of protons available upon stating irradiation in cycle 2 , linear and increased $\mathrm{H}_{2}$ production would be expected.

In addition to the gas evolution rate, the $\prod_{\text {photon }}$ of the system was also determined based on the calculated photon flux and the maximum rate of $\mathrm{H}_{2}$ formation $\left(\mathrm{r}_{\max } \mathrm{H}_{2}{ }^{\mathrm{a}}\right)$. The determination of efficiencies in photocatalysis is a useful metric, especially for allowing for more accurate comparison between studies. The calculation of quantum efficiency and quantum yield is typically determined based on the absorbed light flux. In heterogeneous photocatalytic systems, however, accurately determining this value can be extremely challenging. Therefore, photonic efficiency (or apparent quantum efficiency) is often reported and as such is reported here to be in keeping with common practice. The photon flux was calculated to be $1.12 \times 10^{-4}$ moles $\min ^{-1}$ based on Equation 5, while the $r_{\text {max }} \mathrm{H}_{2}{ }^{\mathrm{a}}$ was calculated as $r \mathrm{H}_{2}$ multiplied by two as $\mathrm{H}_{2}$ formation is a two-electron step.

$$
\text { Equation } 5 \text { Photon flux }=\frac{I \times A_{I}}{\left(\frac{c \times h \times N a}{\lambda}\right)}
$$

Where, ' $I$ ' is the intensity of light $\left(47 \mathrm{~W} \mathrm{~m}^{-2}\right)$ at the surface of the PFPR quartz body ' $A_{I}$ ' is the surface area of the reactor illuminated $\left(0.014 \mathrm{~m}^{2}\right)$, ' $c$ ' is the speed of light, ' $h$ ' is plank's constant, ' $N a$ ' is Avogadro's number and $\lambda$ is the peak wavelength emitted from the lamps (measured to be $\left.355 \mathrm{~nm}, 3.55 \times 10^{-7} \mathrm{~m}\right)$. The $\prod_{\text {photon }}$ was then determined as the ratio between $r_{\max } \mathrm{H}_{2}{ }^{\mathrm{a}}$ and the photon flux, Equation 6. 
Equation $6 \quad \eta_{\text {photo }}(\%)=\frac{r_{\max } H_{2}^{a}}{p h o t \quad f l u x} x 100$

Where ' $\eta_{\text {photon' }}$ ' is photonic efficiency, ' $r_{\max } \mathrm{H}_{2}{ }^{a}$ ' is the maximum rate of $\mathrm{H}_{2}$ production based on the number of electrons involved (moles $\mathrm{min}^{-1}$ ) and 'photon flux' is as described above.

Table 2 shows $\mathrm{Pt} / \mathrm{Pd} / \mathrm{TiO}_{2}-\mathrm{ANFL}$ achieved the highest $\eta_{\text {photon }}$ at $1.4 \%$, with $\mathrm{Pt} / \mathrm{Pd} / \mathrm{TiO}_{2}-$ commercial achieving slightly lower at $1.1 \%$. In comparison, $\mathrm{TiO}_{2}-\mathrm{ANFL}$ achieved a significantly lower $\prod_{\text {photon }}$ of $0.09 \%$, confirming the presence of co-catalysts on the support were crucial to $\mathrm{H}_{2}$ evolution. While a relatively low efficiency, it highlights the potential of using a cost-effective catalyst support synthesised from AFW over that of commercially available alternatives.

Table 2: Calculated efficiencies of $\mathrm{Pt} / \mathrm{Pd} / \mathrm{TiO}_{2}-\mathrm{ANFL}, \mathrm{Pt} / \mathrm{Pd} / \mathrm{TiO}_{2}-$ commercial and $\mathrm{TiO}_{2}-\mathrm{ANFL}$ where $r_{\max } \mathrm{H}_{2}{ }^{\mathrm{a}}$ is the max moles of $\mathrm{H}_{2}$ produced per min, $r_{\max } \mathrm{H}_{2}{ }^{\mathrm{b}}$ is the max rate of $\mathrm{H}_{2}$ as a function of 1 gram of active photocatalyst material present $\left(\mathrm{TiO}_{2}\right)$ and $1 \mathrm{~h}$ of irradiation and $\eta_{\text {photon }}$ was the photonic efficiency of the materials based on the PFPR photon flux of $1.21 \times 10^{-4}$ moles $\min ^{-1}$ and the $r_{\max } \mathrm{H}_{2}{ }^{a}$.

\begin{tabular}{cccc}
\hline Catalyst & $\begin{array}{c}\boldsymbol{r}_{\max } \boldsymbol{H}_{2}{ }^{a} \\
\left(\mathbf{m o l ~ m i n}^{-1}\right)\end{array}$ & $\begin{array}{c}\boldsymbol{r}_{\max } \boldsymbol{H}_{2}{ }^{b} \\
\left(\mathbf{m o l ~ g T i O}_{2}{ }^{-1} \mathbf{h r}^{-1}\right)\end{array}$ & $\begin{array}{c}\mathrm{\eta}_{\text {photon }} \\
(\%)\end{array}$ \\
\hline $\mathrm{Pt} / \mathrm{Pd} / \mathrm{TiO}_{2}-\mathrm{ANFL}$ & $1.72 \times 10^{-6}$ & $7.9 \times 10^{-3}$ & 1.4 \\
$\mathrm{Pt} / \mathrm{Pd} / \mathrm{TiO}_{2}$-Commercial & $1.31 \times 10^{-6}$ & $6.0 \times 10^{-3}$ & 1.1 \\
$\mathrm{TiO}_{2}-\mathrm{ANFL}$ & $1.1 \times 10^{-7}$ & $5.1 \times 10^{-4}$ & 0.09 \\
\hline
\end{tabular}

\section{Conclusion}

Glycerol is known to be a significant waste stream from the production of bio-diesel. In the current work a photoactive catalyst derived from aluminium foil waste (AFW) with high activity (per $\mathrm{g}$ of photoactive material) for the production of $\mathrm{H}_{2}$ from glycerol has been reported. This AFW derived catalyst was found to be more active than the analogous catalyst made from commercially 
available $\mathrm{Al}_{2} \mathrm{O}_{3}$. Under optimum conditions, a steady-state of 4.2 millimole $\mathrm{H}_{2} \mathrm{gTiO}_{2}^{-1} \mathrm{hr}^{-1}$ was achieved after 180 min of irradiation. Despite $\mathrm{TiO}_{2}$ being the only photoactive material present in the catalyst, it was evident that the ANFL and commercial alumina supports were both capable of impacting activity through the increase in proton availability.

In summary, the current work has utilised a catalyst that is synthesised using waste aluminium foil as a resource, limiting the single-use of aluminium foil. In a two-fold approach to improving the eco-friendliness and the circular economy, we have applied this catalyst to the production of $\mathrm{H}_{2}$ from a significant waste stream, i.e. glycerol.

Our approach opens doors for designing an environmentally sustainable catalyst from waste materials which could be of great interest for many industrial applications in the future, including hydrogen production from glycerol (and other biomass feedstocks). It is anticipated that such an approach will make hydrogen production more sustainable, more eco-friendly and less expensive. Furthermore, it is anticipated that the catalyst can be further optimised via the investigation of varying the co-catalyst loadings. Additional future work will investigate such optimised catalysts for other common photocatalytic activities such as dye removal and water remediation applications.

\section{Conflicts of interest}

There are no conflicts to declare.

\section{Notes and references}

We wish to acknowledge the financial support of Invest Northern Ireland via the Centre for Advanced Sustainable Energy (CASE). The authors also wish to thank AgriAD, Alternatech and QUB Sustainable Energy Research Centre for their support.

[1] Fujishima A, Honda K. Electrochemical photolysis of water at a semiconductor electrode. Nature $1972 ; 238: 37-8$. 
[2] Skillen N, McCullagh C, Adams M. Photocatalytic Splitting of Water. vol. 35. 2015. https://doi.org/10.1007/698_2014_261.

[3] Skillen N, Adams M, McCullagh C, Ryu SY, Fina F, Hoffmann MR, et al. The application of a novel fluidised photo reactor under UV-Visible and natural solar irradiation in the photocatalytic generation of hydrogen. Chem Eng J 2016;286. https://doi.org/10.1016/j.cej.2015.10.101.

[4] Li K., An X Park K H, Khraisheh M, Tang J. A critical review of CO2 photoconversion: Catalysts and reactors. Catal Today 2014;224:3-12.

[5] Robertson PKJ. Semiconductor photocatalysis: an environmentally acceptable alternative production technique and effluent treatment process. J Clean Prod 1996;4:203-12. https://doi.org/http://dx.doi.org/10.1016/S0959-6526(96)00044-3.

[6] Boyjoo Y, Sun H, Liu J, Pareek VK, Wang S. A review on photocatalysis for air treatment: From catalyst development to reactor design. Chem Eng J 2017;310, Part:537-59. https://doi.org/http://dx.doi.org/10.1016/j.cej.2016.06.090.

[7] $\mathrm{Hu}$ Z, Mi Y, Ji Y, Wang R, Zhou W, Qiu X, et al. Multiplasmon modes for enhancing the photocatalytic activity of $\mathrm{Au} / \mathrm{Ag} / \mathrm{Cu} 2 \mathrm{O}$ core-shell nanorods. Nanoscale 2019;11:16445-54. https://doi.org/10.1039/C9NR03943K.

[8] Navakoteswara Rao V, Lakshmana Reddy N, Mamatha Kumari M, Ravi P, Sathish M, Kuruvilla KM, et al. Photocatalytic recovery of $\mathrm{H} 2$ from $\mathrm{H} 2 \mathrm{~S}$ containing wastewater: Surface and interface control of photo-excitons in $\mathrm{Cu} 2 \mathrm{~S} @ \mathrm{TiO} 2$ core-shell nanostructures. Appl Catal B Environ 2019;254:174-85. https://doi.org/10.1016/J.APCATB.2019.04.090.

[9] Reddy CV, Reddy IN, Reddy KR, Jaesool S, Yoo K. Template-free synthesis of tetragonal Codoped $\mathrm{ZrO} 2$ nanoparticles for applications in electrochemical energy storage and water treatment. Electrochim Acta 2019;317:416-26. https://doi.org/10.1016/J.ELECTACTA.2019.06.010.

[10] Reddy KR, Reddy CV, Nadagouda MN, Shetti NP, Jaesool S, Aminabhavi TM. Polymeric graphitic carbon nitride (g-C3N4)-based semiconducting nanostructured materials: Synthesis 
methods, properties and photocatalytic applications. J Environ Manage 2019;238:25-40. https://doi.org/10.1016/J.JENVMAN.2019.02.075.

[11] Reddy CV, Reddy IN, Akkinepally B, Harish VVN, Reddy KR, Jaesool S. Mn-doped ZrO2 nanoparticles prepared by a template-free method for electrochemical energy storage and abatement of dye degradation. Ceram Int 2019;45:15298-306.

https://doi.org/10.1016/J.CERAMINT.2019.05.020.

[12] Mehta A, Mishra A, Basu S, Shetti NP, Reddy KR, Saleh TA, et al. Band gap tuning and surface modification of carbon dots for sustainable environmental remediation and photocatalytic hydrogen production - A review. J Environ Manage 2019;250:109486. https://doi.org/10.1016/J.JENVMAN.2019.109486.

[13] Venkata Reddy C, Reddy IN, Akkinepally B, Reddy KR, Shim J. Synthesis and photoelectrochemical water oxidation of $(\mathrm{Y}, \mathrm{Cu})$ codoped $\alpha$-Fe2O3 nanostructure photoanode. $\mathrm{J}$ Alloys Compd 2020;814:152349. https://doi.org/10.1016/J.JALLCOM.2019.152349.

[14] Chen W-T, Chan A, Sun-Waterhouse D, Llorca J, Idriss H, Waterhouse GIN. Performance comparison of $\mathrm{Ni} / \mathrm{TiO} 2$ and $\mathrm{Au} / \mathrm{TiO} 2$ photocatalysts for $\mathrm{H} 2$ production in different alcohol-water mixtures. J Catal 2018;367:27-42. https://doi.org/https://doi.org/10.1016/j.jcat.2018.08.015.

[15] Zheng X-J, Wei L-F, Zhang Z-H, Jiang Q-J, Wei Y-J, Xie B, et al. Research on photocatalytic H2 production from acetic acid solution by $\mathrm{Pt} / \mathrm{TiO} 2$ nanoparticles under $\mathrm{UV}$ irradiation. Int $\mathrm{J}$ Hydrogen Energy 2009;34:9033-41. https://doi.org/http://dx.doi.org/10.1016/j.ijhydene.2009.09.019.

[16] Caravaca A, Jones W, Hardacre C, Bowker M. H2 production by the photocatalytic reforming of cellulose and raw biomass using Ni, Pd, Pt and Au on titania. Proc R Soc A Math Phys Eng Sci $2016 ; 472$.

[17] Zhang G, Ni C, Huang X, Welgamage A, Lawton LA, Robertson PKJ, et al. Simultaneous cellulose conversion and hydrogen production assisted by cellulose decomposition under UV-light 
photocatalysis. Chem Commun 2016;52:1673-6. https://doi.org/10.1039/C5CC09075J.

[18] Bowker M, Davies PR, Al-Mazroai L. Photocatalytic Reforming of Glycerol over Gold and Palladium as an Alternative Fuel Source. Catal Letters 2008;128:253. https://doi.org/10.1007/s10562-008-9781-1.

[19] Bewley BR, Berkaliev A, Henriksen H, Ball DB, Ott LS. Waste glycerol from biodiesel synthesis as a component in deep eutectic solvents. Fuel Process Technol 2015;138:419-23. https://doi.org/10.1016/J.FUPROC.2015.05.025.

[20] Estahbanati MRK, Feilizadeh M, Iliuta MC. Photocatalytic valorization of glycerol to hydrogen: Optimization of operating parameters by artificial neural network. Appl Catal B Environ 2017;209:483-92. https://doi.org/https://doi.org/10.1016/j.apcatb.2017.03.016.

[21] Jiang X, Fu X, Zhang L, Meng S, Chen S. Photocatalytic reforming of glycerol for H2 evolution on $\mathrm{Pt} / \mathrm{TiO} 2$ : fundamental understanding the effect of co-catalyst $\mathrm{Pt}$ and the Pt deposition route. J Mater Chem A 2015;3:2271-82. https://doi.org/10.1039/C4TA06052K.

[22] I. AO, Abu-Dahrieh JK, McLaren M, Laffir F, Nockemann P, Rooney D. A Facile Green Synthetic Route for the Preparation of Highly Active $\gamma$-A12O3 from Aluminum Foil Waste. Nat Sci Reports 2017.

[23] Osman AI, Abu-Dahrieh J, McLaren M, Laffir F, Rooney DW. Characterisation of Robust Combustion Catalyst from Aluminium Foil Waste. ChemistrySelect 2018;3:1545-50. https://doi.org/10.1002/slct.201702660.

[24] Osman AI, Abu-Dahrieh JK, Laffir F, Curtin T, Thompson JM, Rooney DW. A bimetallic catalyst on a dual component support for low temperature total methane oxidation. Appl Catal B Environ 2016;187:408-18. https://doi.org/https://doi.org/10.1016/j.apcatb.2016.01.017.

[25] Murashkina AA, Murzin PD, Rudakova A V, Ryabchuk VK, Emeline A V, Bahnemann DW. Influence of the Dopant Concentration on the Photocatalytic Activity: Al-Doped TiO2. J Phys Chem C 2015;119:24695-703. https://doi.org/10.1021/acs.jpcc.5b06252. 
[26] Slamet, Ratnawati, Gunlazuardi J, Dewi EL. Enhanced photocatalytic activity of Pt deposited on titania nanotube arrays for the hydrogen production with glycerol as a sacrificial agent. Int J Hydrogen Energy 2017;42:24014-25. https://doi.org/https://doi.org/10.1016/j.ijhydene.2017.07.208.

[27] Vaiano V, Lara MA, Iervolino G, Matarangolo M, Navio JA, Hidalgo MC. Photocatalytic H2 production from glycerol aqueous solutions over fluorinated Pt-TiO2 with high $\{001\}$ facet exposure. J Photochem Photobiol A Chem 2018;365:52-9. https://doi.org/10.1016/J.JPHOTOCHEM.2018.07.032.

[28] Fujita S, Kawamori H, Honda D, Yoshida H, Arai M. Photocatalytic hydrogen production from aqueous glycerol solution using $\mathrm{NiO} / \mathrm{TiO} 2$ catalysts: Effects of preparation and reaction conditions. Appl Catal B Environ 2016;181:818-24. https://doi.org/10.1016/J.APCATB.2015.08.048.

[29] Liu R, Yoshida H, Fujita S, Arai M. Photocatalytic hydrogen production from glycerol and water with $\mathrm{NiOx} / \mathrm{TiO} 2$ catalysts. Appl Catal B Environ 2014;144:41-5. https://doi.org/10.1016/J.APCATB.2013.06.024.

[30] Yang J, Yan H, Wang X, Wen F, Wang Z, Fan D, et al. Roles of cocatalysts in Pt-PdS/CdS with exceptionally high quantum efficiency for photocatalytic hydrogen production. J Catal 2012;290:151-7. https://doi.org/http://dx.doi.org/10.1016/j.jcat.2012.03.008. 